\title{
Expression of molecular equivalent of hypothalamic-pituitary-adrenal axis in adult retinal pigment epithelium
}

\author{
Michal A Zmijewski, Rajesh K Sharma ${ }^{1}$ and Andrzej T Slominski \\ Department of Pathology and Laboratory Medicine, 'Department of Ophthalmology, University of Tennessee Health Science Center, 930 Madison Avenue, \\ RM525, Memphis, Tennessee 38163, USA \\ (Requests for offprints should be addressed to A T Slominski; Email: aslominski@utmem.edu) \\ (The present address of R K Sharma is at the Department of Ophthalmology, University of Florida, Jacksonville, Florida, USA)
}

\begin{abstract}
We have investigated expression of molecular elements of the hypothalamic-pituitary-adrenal (HPA) axis in the human retinal pigment epithelium (RPE) cells. The presence of corticotropinreleasing factor (CRF); urocortins I, II and III; CRF receptor type 1 (CRFR1); POMC and prohormone convertases 1 and 2 (PC1 and PC2) mRNAs were shown by RT-PCR; the protein products were detected by ELISA, western blot or immunocytochemical methods in an ARPE-19 cell line derived from an adult human donor. CRFR 2 was below the level of detectability. The CRFR 1 was functional as evidenced by CRF stimulation of cAMP and inositol triphosphate production as well as by ligand induction of transcriptional activity of inducible cis-elements cAMP responsive element (CRE), activator protein 1 responsive
\end{abstract}

element (AP-1) and POMC promoter) in ARPE-19 using luciferase reporter assay. Immunoreactivities representative of CRF, pre-urocortin, CRFR1 receptor and ACTH were also detected in mouse retina by in situ immunocytochemistry. Finally, using RT-PCR, we detected expression of genes encoding four key enzymes participating in steroids synthesis (CYP11A1, CYP11B1, CYP17 and CYP21A2) and showed transformation of progesterone into cortisol-immunoreactivity in cultured ARPE-19 cells. Therefore, we suggest that ocular tissue expresses CRF-driven signalling system that follows organisational structure of the HPA axis.

Journal of Endocrinology (2007) 193, 157-169

\section{Introduction}

Corticotropin-releasing factor (CRF) is the most proximal element of the hypothalamic-pituitary-adrenal (HPA) axis, a system that coordinates the body response to systemic stress (Selye 1936, Vale et al. 1981, Chrousos 1995, Aguilera 1998). Physiological actions of CRF and related peptides such as urocortins I-III (Ucn I-III) are mediated through interactions with membrane-bound receptors, CRFR1 and CRFR2 (Perrin \& Vale 1999, Grammatopoulos \& Chrousos 2002, Hillhouse \& Grammatopoulos 2006, Slominski et al. 2006b). Activation of CRF receptors leads to stimulation of adenylate cyclase, phospholipase C and calcium channels (Perrin \& Vale 1999, Hillhouse \& Grammatopoulos 2006). Subsequent production of cyclic AMP (cAMP) and inositol triphosphate $\left(\mathrm{IP}_{3}\right)$ activates signal transduction pathway and enhances expression of the proopiomelanocortin (POMC), followed by secretion of POMC-derived adrenocorticotrophic hormone (ACTH; Grammatopoulos \& Chrousos 2002, Hillhouse \& Grammatopoulos 2006). ACTH stimulates the production and release of cortisol from the adrenal cortex, which by a feedback mechanism attenuates hypothalamic CRF and pituitary POMC production (Chrousos 1995). Another POMC product, $\alpha$-melanocyte-stimulating hormone (MSH), interacts with its melanocortin receptor type $1\left(\mathrm{MC}_{1}\right)$ and stimulates melanogenesis in the skin (Slominski et al. 2004a).

There is growing evidence that CRF and related peptides can act as local modulators of stress in the peripheral organs such as skin, gestational tissues, immune system, pancreas, liver, gastrointestinal tract, skeletal muscle, heart, lung and endocrine organs (ovaries, testes, adrenals and thyroid glands; Slominski et al. 2001, 2004b, 2006b, Linton et al. 2001, Kempuraj et al. 2004, Hillhouse \& Grammatopoulos 2006). However, the presence of an analogue of the HPA axis in the ocular tissue has not been documented. Nevertheless, CRF was shown to be involved in the development of the retina (Bagnoli et al. 2003) and pathogenesis of experimental autoimmune uveoretinitis in rodents (Mastorakos et al. 1995). CRF immunoreactivity is also found in amacrine cells (Lindqvist et al. 2003), and the expression of POMC and its receptors $\left(\mathrm{MC}_{3}, \mathrm{MC}_{4}\right.$ and $\left.\mathrm{MC}_{5}\right)$ were detected in adult rat retina (Lindqvist et al. 2003). POMC expression, $\boldsymbol{\alpha}-\mathrm{MSH}$ immunoreactivity and receptors for POMC peptides have also been found in the developing chick retina (Teshigawara et al. 2001).

The retinal pigment epithelial (RPE) cells form a monolayer of highly specialised pigmented cells located between the neural retina and the vascular choroid that 
influence their structure and function (Sharma \& Ehinger 2003). These cells are exposed to pathological stresses, yet the mechanism of stress response has not been well characterised (Sharma et al. 1995).

Since other pigmented cells such as the skin melanocytes express a functional analogue of HPA axis (Slominski et al. 2000, 2004a, 2005), we investigated whether the human adult ARPE-19 express molecular elements of this axis. In vitro observations from cell line model were further confirmed in vivo by immunohistochemical analysis of mouse eye.

\section{Materials and Methods}

\section{Cell culture and tissues}

A widely researched human adult RPE cell line, ARPE-19, was obtained from American Type Culture Collection (ATTC, Manassas, VA, USA) and maintained in T-25 culture flasks (Becton Dickinson, Franklin Lake, NJ, USA) at $37^{\circ} \mathrm{C}$ in an atmosphere of $95 \%$ air and $5 \% \mathrm{CO}_{2}$. The culture medium contained Dulbecco's modified Eagle's medium (DMEM) with 5\% foetal bovine serum (FBS), insulin $(50 \mu \mathrm{g} / \mathrm{ml}$ and an antibiotic-antimycotic mixture $(10000$ units/penicillin G Sodium, $10 \mathrm{mg} /$ streptomycin sulphate and $25 \mu \mathrm{g} /$ amphotericin B; Gibco, Invitrogen Corp.). Cells were passaged weekly and fed every second day. Culture passages (p) 24-37 were used in the experiments. Cells were plated at 250000 cells $/ \mathrm{cm}^{2}$ on $75 \mathrm{~cm}^{3}$ flasks and allowed to become confluent. The cells were detached from the flask by trypsinisation $(0 \cdot 05 \%$ trypsin/EDTA for $5 \mathrm{~min})$ and washed in PBS; pellets obtained were used for protein or total RNA preparations (see below).

For immunohistochemistry, eyes were obtained from adult $(n=3)$ C57/BL6 mice. The eyes were briefly fixed in $4 \%$ paraformaldehyde in PBS $(0.1 \mathrm{M}$ phosphate, $0.85 \% \mathrm{NaCl}$; $\mathrm{pH} 7 \cdot 4)$. The anterior segment of the eyes was removed and the posterior segment was placed in the same fixative for an additional $24 \mathrm{~h}$. The tissue was rinsed with PBS and then sequentially processed in a buffer containing 5, 10 and 20\% sucrose. The eyes were stored in PBS with 20\% sucrose until sectioned. Sections of $12 \mu \mathrm{m}$ thickness were cut on a cryostat and mounted on glass slides coated with gelatin. They were subsequently stored at $-70{ }^{\circ} \mathrm{C}$. Sagittal sections close to the optic nerve were used for immunohistochemistry. Animals were ethically treated and the protocols were approved by the local IACUC at the UTHSC.

\section{cDNA preparation and $P C R$ assays}

Total RNA was prepared using a total RNA extraction kit (Qiagen) supplemented with an RNAse-free DNAse Set (Qiagen). Two micrograms of total RNA were reverse transcribed with SuperScript First-Strand Synthesis System (Applied Biosystems, Foster City, CA, USA). Quality and quantity of all samples were standardised by the amplification of housekeeping gene glyceraldehyde-3-phosphate dehydrogenase (GAPDH) and 18S rRNA subunit as described previously (Pisarchik \& Slominski 2001, Slominski et al. 2005). In order to confirm that cDNA is free chromosomal DNA contamination, mRNA templates were incubated without reverse transcriptase in reaction mixture and PCR amplifications of GAPDH were performed. Only samples that were free DNA contamination were used for further experiments. Primers used for PCR amplification were synthesised by Integrated DNA Technology Inc. (Coralville, IA, USA) and were listed in Table 1. PCRs were carried out as described previously, using PCR Master Mix (Promega) and $0.4 \mathrm{mM}$ of each primer (see Table 1 for details). Amplification products were separated by agarose gel electrophoresis and visualised by ethidium bromide staining. In order to verify the length of RT-PCR products, 100 bp DNA Ladder (O'RangeRuler, Fermentas, Hanover, MD, USA) was used with the exception of Fig. 2A and E where low range DNA Ladder (MassRuler, Fermentas) and Fig. 2D where $1 \mathrm{~kb}$ DNA Ladder (NEB, Ipswich, MA, USA were used.

\section{Western blotting}

ARPE-19 cells were detached by trypsin and centrifuged at $1000 \mathrm{~g}$ for $10 \mathrm{~min}$ at $4{ }^{\circ} \mathrm{C}$. The cell pellets were then washed with $\mathrm{PBS}(\mathrm{pH} 7 \cdot 4)$ and stored at $-80^{\circ} \mathrm{C}$. For protein isolation, frozen cell pellets were solubilised by pipetting into an ice-cold $20 \mathrm{mM}$ Tris, $\mathrm{pH} 7 \cdot 4,1 \%$ Triton X-100 buffer supplemented with Protease inhibitor cocktail (Sigma). Cellular homogenates were centrifuged at $16000 \mathrm{~g}$ for $10 \mathrm{~min}$ at $4{ }^{\circ} \mathrm{C}$ and the supernatants used for assays were stored at $-80^{\circ} \mathrm{C}$. Forty micrograms of total protein extract were resolved on $12 \%$ SDS-PAGE, transferred to Immobilon$\mathrm{P}$ poly(vinylidene difluoride) membrane (Millipore Corp, Bedford, MA, USA) for $1.5 \mathrm{~h}$ at $4{ }^{\circ} \mathrm{C}$ and blocked overnight at cold room in 5\% non-fat powdered milk in TBST $(50 \mathrm{mM}$ Tris, pH 7.5, $150 \mathrm{mM} \mathrm{NaCl}, 0 \cdot 01 \%$ Tween 20). For immunodetection of proteins, membranes were incubated with goat anti-CRF-R1 (C20) antibodies (dilution 1:200; Santa Cruz Biotechnology, Santa Cruz, CA, USA) for $3 \mathrm{~h}$, then washed once with 5\% non-fat, dry milk in TBST, twice with TBST, and then incubated for $1 \mathrm{~h}$ with anti-goat antibodies coupled to horseradish peroxidase (dilution 1:2000; Santa Cruz Biotechnology). Membranes were washed twice in TBST and once in TBS and bands were visualised by Super Signal West Pico (Pierce Biotechnology, Rockford, IL, USA). The protein concentration was determined with a BCA protein assay kit (Pierce Biotechnology) and BSA used as a positive control. Protein ladder was purchased from Fermentas.

\section{ELISA assays}

ARPE-19 p24, p30 and human immortalised HaCaT keratinocyte cells were grown in DMEM with $5 \%$ charcoal 


\begin{tabular}{|c|c|c|c|c|}
\hline & Primer & Primer location & Fragment size & Reference \\
\hline \\
\hline CRF & MZO25 5'-GCCCTGGCCATTTCCAAGAC-3' & Exon 2 & 415 OP & (1) (19) \\
\hline \multirow[t]{2}{*}{ Ucn I } & MZ026 5'-CAGGCGAGCGGCCGCG-3' & Exon 2 & 145 bp & Bamberger et al. (1998) \\
\hline & MZ027 5'-CTTGCCCACCGAGTCGAAT-3' & Exon 2 & & \\
\hline \multirow[t]{2}{*}{ Ucn II } & MZ103 5'-GTGTCGGCCACTGCTGAGCCTGAGAGA-3' & Exon 2 & $195 \mathrm{bp}$ & Imperatore et al. (2006) \\
\hline & MZ104 5'-ATCTGATATGACCTGCATGACAGTGGCT-3' & Exon 2 & & \\
\hline Ucn III & P575 5'-TGAGCAAGAGGAGCTTCCAC-3' & Exon 1 & 318 bp & * \\
\hline \multirow{14}{*}{ CRFR1 } & CRFR1 fragment spanning exons $2-7$ & Exon 1 & & Pisarchik \& Slominski (2001) \\
\hline & First pair of primers & Exon 2 & PCR fragments after second round of amplification & 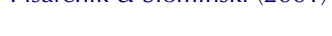 \\
\hline & P110, 5'-TCCGTCTCGTCAAGGCCCTTC-3' & Exon 7 & 479 bp Insertion of cryptic exon between exons 4 and 5 (CRFR1 h) & \\
\hline & P111, 5'-GGCTCATGGTTAGCTGGACCAC-3' & & 369 bp (absent exon 6 CRFR $1 \alpha, d, f, g$ ) & \\
\hline & Nested primers & & 249 bp Exons 3 and 6 are absent (CRFR1c) & \\
\hline & P112, 5' -TGTCCCTGGCCAGCAACATCTC- $3^{\prime}$ & Exon 2 & 163 bp exons 3, 4 and 6 are absent (frameshift, CRFR1e) & \\
\hline & P113, 5'-AGTGGATGATGTTTCGCAGGCAC-3' & Exon 7 & & \\
\hline & CRFR1 fragment spanning exons $9-14$ & & PCR fragments after second round of amplification & Pisarchik \& Slominski (2001) \\
\hline & First pair of primers & & 336 bpAll exons are present (CRFR1 $\alpha, \beta, \mathrm{c})$ & \\
\hline & P114 5'-CCATTGGGAAGCTGTACTACGAC-3' & Exon 9 & 294 bp Exon 13 is absent (CRFR1d) & \\
\hline & P115 5'-GCTTGATGCTGTGAAAGCTGACAC-3' & Exon 14 & $200 \mathrm{bp}$ Exon 12 is absent (frameshift, CRFR1f) & \\
\hline & Nested primers & & $\begin{array}{l}114 \text { bp Exon 11, } 27 \text { bp of exon } 10 \text { and } 28 \text { bp of exon } 12 \text { are } \\
\text { absent (CRFR1g) }\end{array}$ & \\
\hline & P116 5'-GGGTGTACACCGACTACATCTAC-3' & Exon 9 & & \\
\hline & P117 5'TCTTCCGGATGGCAGAACGGAC-3' & Exon 14 & & \\
\hline \multirow[t]{2}{*}{ POMC } & POMC gEfor 5'-GAGGGCAAGCGCTCCTACTCC-3' & Exon 3 & 261 bp & Slominski et al. (1995) \\
\hline & POMC gErev 5'-GGGGCCCTCGTCCTTCTTCTC-3' & Exon 3 & & \\
\hline \multirow[t]{2}{*}{ POMC } & POMC PXfor 5'-CTACGGCGGTTTCATGACCT-3 & Exon 3 & 100 bp & Slominski et al. (2005) \\
\hline & POMC PXrev 5'-CCCTCACTCGCCCTTCTTG-3' & Exon 3 & & \\
\hline & First pair of primers & & & Slominski et al. (2004c) \\
\hline \multirow{5}{*}{ NM_000781 } & P561 5'-GCCTTTGAGTCCATCACTAAC-3' & Exon 4 & 628 bp & \\
\hline & P562 5'-CCAGTGTCTTGGCAGGAATC-3' & Exon 7 & & \\
\hline & Nested Primers & & 390 bp & \\
\hline & P563 5'-ATGTGGCTGCATGGGACGTG-3' & Exon 4 & & \\
\hline & P564 5'-TCTGCAGGGTCACGGAGATG-3' & Exon 7 & & \\
\hline \multirow[t]{2}{*}{ CYP11B1 } & MZ127 5'-CTGGGACATTGGTGCGC-3' & Exon 8/9 & 215 bp & Lin et al. (2006) \\
\hline & MZ128 5-GTGTTTCAGCACATGGT-3' & Exon $9 / 10$ & & \\
\hline CYP17 & First pair of primers & & 251 bp & * \\
\hline \multirow[t]{5}{*}{ NM_000102 } & P565 5'-CTCTAGACATCGCGTCCAAC-3' & Exon 2 & & \\
\hline & P566 5'-GAAGCAGATCAAGGAGATGAC-3' & Exon 3 & & \\
\hline & Nested Primers & & 222 bp & \\
\hline & P587 5'-TCGCGTCCAACAACCGTAAG-3' & Exon 2 & & \\
\hline & P588 5'-CATTGGTTACCGCCACGAAG-3' & Exon 3 & & \\
\hline \multirow{6}{*}{ NM_0005002 } & First pair of primers & & 299 bp & * \\
\hline & P593 5'-CTGAAGCAGGCCATAGAGAAG-3' & Exon 7 & & \\
\hline & P594 5'-AGTTCGTGGTCTAGCTCCTC-3' & Exon 8 & & \\
\hline & Nested primers & & 199 bp & \\
\hline & P396 5'-TGGAGGGACATGATGGACTAC-3' & Exon 7 & & \\
\hline & P397 5'-CСTGCAGTCGCTGCTGAATC-3' & Exon 8 & & \\
\hline
\end{tabular}

*refers to current paper 
FBS and antibiotic mixture until $80 \%$ confluent. Conditioned media and cells were collected separately. Media from ARPE19 cells were concentrated in C18 Sep-columns (Peninsula Laboratories, San Carlos, CA, USA). CRF peptide concentration in the supernatants was measured with ELISA kit for CRF (Phoenix Pharmaceuticals, Belmont, CA, USA) and normalised for total protein content in cell lysates (quantified with BCA reagent; Pierce Biotechnology). In order to detect cortisol production in human ARPE-19 (passage 28), cells were seeded at a concentration of 500000 cells $/ 10 \mathrm{~cm}$ Petri dish in DMEM supplemented with 5\% FBS and antibiotic mixture. After overnight incubation, cultures were washed with PBS and media were replaced with serum-free DMEM containing progesterone $10^{-6}$ or $10^{-5} \mathrm{M}$. After $24 \mathrm{~h}$ of incubation with CRF or ACTH $\left(10^{-7} \mathrm{M}\right)$, medium was collected and the steroids were extracted with methylene chloride as described previously (Slominski et al. 2004c, 2005). The extracts were dried under nitrogen and then reconstituted in assay buffer and used for cortisol quantification with the BioQuant Cortisol ELISA kit (Bio-Quant, San Diego, CA, USA). The amount of cortisol was calculated from cortisol standard curve and presented as nanograms per millilitre of the medium.

\section{CRF treatment and CAMP assays}

ARPE-19 cells were grown on 96-well plates until confluent (2-3 days) in DMEM containing 5\% FBS and antibiotics. Twelve hours prior to experiments, the medium was replaced with DMEM containing 5\% FBS, antibiotics and $0.5 \mathrm{mM}$ 3-isobutyl-1-methylxanthine. The cells were incubated with serial dilutions of the CRF (Sigma) for $1 \mathrm{~h}$ at $37^{\circ} \mathrm{C}$ and $5 \%$ $\mathrm{CO}_{2}$ as described previously (Pisarchik \& Slominski 2004, Slominski et al. 2006a). Cyclic AMP concentration in cell lysates was measured by cAMP functional assay kit (Packard BioScience, Meriden, CT, USA). The assay was based on the competition between endogenous and exogenous cAMP (biotinylated) to a specific antibody (acceptor beads) in the presence of streptavidin-coated donor beads. The signal (excitation $680 \mathrm{~nm}$ and emission 520-620 nm) was measured by universal microplate reader Fusion $\alpha$ (Packard BioScience) and was indirectly proportional to the concentration of endogenous cAMP. The concentration of endogenous cAMP was corrected to a standard curve prepared by serial dilution of cAMP (Packard BioScience).

\section{Inositol triphosphate $\left(\mathrm{IP}_{3}\right)$ assays}

$\mathrm{IP}_{3}$ was measured by an amplified luminescent proximity homogenous assay (AlphaScreen Glutathione-S-Transferase (GST) detection kit and AlphaScreen $\mathrm{IP}_{3}$ Assay Supplement, both from Packard BioScience) as described previously (Zbytek \& Slominski 2005, Slominski et al. 2006a). In brief, cells were detached with a trypsin/EDTA solution, washed once with PBS and suspended at a concentration of 2500 cells $/ 10 \mu$ per well in 96-well white opaque plates in PBS buffer containing $15 \mathrm{mM}$
HEPES, pH 7 4. Cells were stimulated with CRF (Sigma) at the indicated concentrations for $0-120 \mathrm{~s}$. The reaction was stopped with $1 \cdot 05 \%$ perchloric acid. Production of $\mathrm{IP}_{3}$ was assayed by incubation of the reaction mixture with $\mathrm{IP}_{3}$-binding protein followed by detection with a solution containing biotinylated $\mathrm{IP}_{3}$ analogue, streptavidin-coated donor beads and anti-GST acceptor beads. The signal (excitation $680 \mathrm{~nm}$ and emission $520-620 \mathrm{~nm}$ ) was measured by universal microplate reader Fusion $\alpha$ (Packard BioScience) and was indirectly proportional to the concentration of endogenous $\mathrm{IP}_{3}$. The raw data $(n=3$ experiments) were correlated with a standard curve generated with D-myo-inositol 1,4,5-triphosphate (Sigma).

\section{Reporter gene constructs activity}

APRE-19 cells were transfected using lipofectamine and PLUS reagents (Invitrogen) with firefly luciferase reporter gene plasmids pCRE-Luc, pAP1-Luc, pPOMC-Luc and with phRL-TK plasmid (coding Renilla luciferase and used as normalisation control; Promega). Plasmids pCRE-Luc (containing four cAMP responsive elements) and pAP1-Luc (five AP1 responsive elements) were described previously (Pisarchik \& Slominski 2004). Plasmid pPOMC-Luc contained the sequence -771 to -8 of the human POMC promoter (Slominski et al. 2005, 2006b, Zbytek et al. 2006). After transfection, the cells were treated with serial dilution of CRF in DMEM medium (5\% charcoal FBS and antibiotics) for $24 \mathrm{~h}$. The firefly luciferase and Renilla luciferase signals were recorded with a TD-20/20 luminometer (Turner Designs, Sunnyvale, CA, USA) using Dual-Luciferase Reporter Assay System (Promega). After subtracting background luminescence, the ratio of firefly signal to Renilla signal was calculated. The values obtained were divided by the mean of control (untreated) cells.

\section{Statistical analyses}

Data were presented as means \pm s.E.M. $(n=3-4)$ and analysed with Student's $t$-test (for two groups) or one-way ANOVA with appropriate post hoc tests (for more than two groups) using Prism 4.00 (GraphPad Software, San Diego, CA, USA). Statistically significant differences were denoted with asterisks or $P$ values were shown. The dose-response curve fitting and $\mathrm{EC}_{50}$ calculations were also performed using Prism $4 \cdot 0$ software.

\section{Immunocytochemistry and histochemistry}

Cells were seeded onto 8-well Lab-Tek II chamber slides (Nalge Nunc, Inc., Naperville, IL, USA). Subconfluent cells were fixed with $4 \%$ paraformaldehyde in PBS for $10 \mathrm{~min}$. The cells were permeabilised with $0 \cdot 1 \%$ Triton X-100 (in PBS) for $5 \mathrm{~min}$ and blocked with 1\% BSA (in PBS) for $30 \mathrm{~min}$. Immunostaining was performed as described previously (Slominski et al. 2004b, 2006a). Briefly, immunostaining was carried out with antisera: goat anti-CRF-R1 (1:200) and antiurocortin I (1:100; both from Santa Cruz Biotechnology). 
ACTH immunoreactivity was detected by rabbit anti-ACTH antibody (1:200, AFP173P, NIADDK, Bethesda, MD, USA). The antigens were visualised with an fluorescein isothiocyanate (FITC)-conjugated secondary anti-goat or anti-rabbit antibody (1:200 in 1\% BSA in PBS for $1 \mathrm{~h})$. The slides were extensively washed with PBS between staining and then mounted with Vectashield Mounting Medium with propidium iodide or 4',6-diamidino-2-phenylindole (DAPI; Vector Laboratories, Burlingame, CA, USA). Background controls were performed by omitting the primary antibodies.

To determine in situ antigen expression, formalin-fixed cryosections were first incubated in the normal serum of the animal, in which the secondary antibody was raised, followed by incubation with the primary antibody as above (except that goat anti-CRF-R1 antibody was used at 1:100 dilution) in a humidified chamber overnight. Optimum working concentration and incubation time for the antibody were determined earlier in pilot experiments. After incubation, the slides were rinsed with $\mathrm{PBS}$ and incubated for $1 \mathrm{~h}$ in an appropriate secondary antibody (anti-goat or anti-rabbit) conjugated with Cy3 (Jackson Laboratories, West Grove, PE, USA). The slides were rinsed again in PBS and mounted with Vectashield (Vector Laboratories). At least three slides from each specimen were stained, and in each experiment, controls were obtained by omitting the primary antibody. Slides were examined under a fluorescent microscope. Digital fluorescence and bright field micrographs were taken using a Nikon camera.

\section{Results}

$C R F$ and urocortins are expressed in ARPE-19 cells

By RT-PCR, we detected the mRNAs for CRF, Ucn I, Ucn II and Ucn III in adult ARPE-19 cells (Fig. 1A). The RT-PCR product of $413 \mathrm{bp}$ corresponding to the predicted fragment of exon 2 of the CRF gene (Slominski et al. 1995) was detected in p24, but not in p30 of ARPE-19 cells. Brain and $\mathrm{HaCaT}$ keratinocyte cDNAs were used as positive controls. The observation was confirmed in three independent experiments, indicating that the expression of CRF gene is influenced by a number of passages in culture. As predicted for Ucn I, Ucn II and Ucn III genes, the corresponding fragments of $145 \mathrm{bp}$ (Bamberger et al. 1998), $195 \mathrm{bp}$ (Imperatore et al. 2006) and 318 bp (Table 1) were detected in p24 and p30 of ARPE-19 cells (Fig. 1B-D). Sequences of the amplified fragments had 100\% homology with corresponding genes as documented previously (Pisarchik et al. 2004, Slominski et al. 2004b).

CRF and Ucn I mRNAs were translated into corresponding protein products as demonstrated in Fig. 1A, E and F. Specifically, the presence of CRF peptide in the ARPE-19 cells was detected by ELISA assay in both early and late passages with concentrations only slightly lower than those in control HaCaT keratinocytes (Fig. 1E). Immunocytochemical analysis has also demonstrated the presence of Ucn I immunoreactivity (Fig. 1A and F).
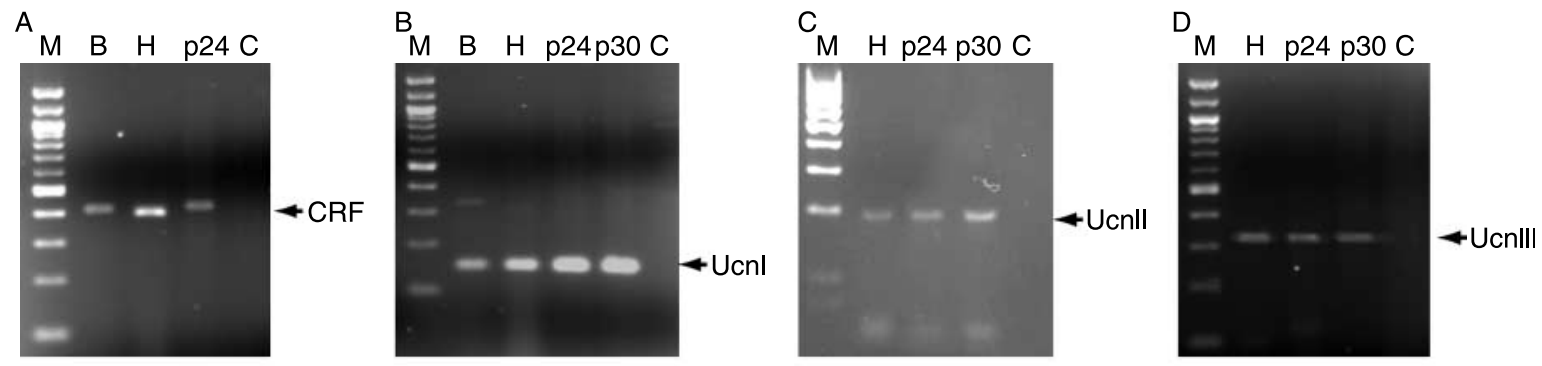

$\mathrm{E}$

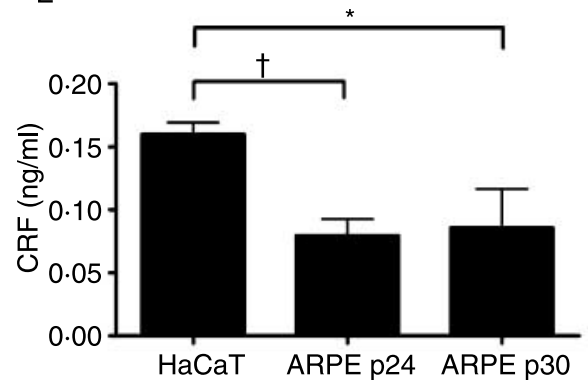

F

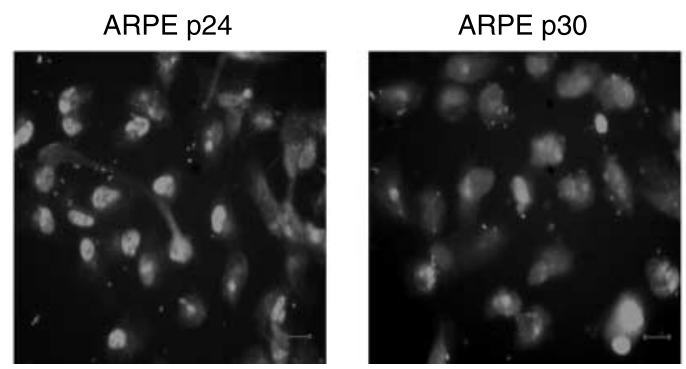

Figure 1 Expression of CRF, urocortins I, II and III (stresscopin) in human ARPE-19 cells. RT-PCR detection of mRNA of CRF (A), Ucn I (B) Ucn II (C) and Ucn III (D). For panels A-D: 100 kb DNA ladder, M; brain, B; immortalised HaCaT keratinocytes, H; ARPE-19 passages 24, p24; and 30, p30; negative control without CDNA, C. (E) Detection of CRF in whole cell lysates of ARPE-19 cells in comparison with HaCaT keratinocytes by ELISA. ${ }^{*} P<0.05,{ }^{+} P<0.01(n \leq 3)$. (E) Immunocytochemical detection of urocortin I in human ARPE-19 cells, passages 24 (p24) and 30 (p30). Colour panels and control experiments are shown in supplementary Fig. 1 (see supplementary data in the online version of Journal of Endocrinology at http://joe.endocrinologyjournals.org/content/vol193/issue1/). Bar, $25 \mu \mathrm{m}$. 
POMC, $\mathrm{PC} 1$ and $\mathrm{PC} 2$ genes and $A C T H$ antigens are expressed in ARPE-19 cells

Similar levels of POMC gene expression were detected independently, with two sets of primers in early and late passages of ARPE-19 line, being slightly lower than those in the brain (Fig. 2A and B). RT-PCR products of $261 \mathrm{bp}$ (Slominski et al. 1995) and 100 bp (Slominski et al. 2005) were specific for exon 3 of the POMC gene, e.g. $100 \%$ of their sequence homology with POMC was shown in previous experiments (Pisarchik \& Slominski 2004, Slominski et al. 2005). Since processing of POMC precursor requires the presence of both prohormone convertases 1 and 2 (PC1 and PC2), we have performed RT-PCR analysis of RNA isolated from p24 and p30 of ARPE-19 cells. PC2 mRNA was detected in both passages, while PC1 was detected only in $\mathrm{p} 24$, indicating a potential for age-dependent differences in POMC processing (Fig. 2D and E). Immunocytochemical analyses detected ACTH immunoreactivity in both passages of ARPE-19 cells (supplementary figure 1C and Fig. 2C) indicating that POMC message is translatable in RPE cells.
Expression of CRFR1 in ARPE-19 cells

The unique set of nested PCR primers spanning exons 2-7 and 9-14 of CRFR1 were used to detect expression of splicing variants of CRFR1 as described previously (Pisarchik \& Slominski 2001).p24 of ARPE-19 cells expressed isoforms CRFR $1 \alpha$, e, $f$ and $g$, while $p 30$ expressed only CRFR $1 \alpha$ (Fig. 3A and B). The expression of CRFR2 was below the level of detection by RT-PCR using primers amplifying common fragment of CRFR2 (Slominski et al. 2004b); however, the CRFR2 transcript was detected in the brain mRNA used as a positive control (data not shown).

Western blotting analysis (Fig. 3C) revealed that lysates of ARPE-19 cells (p24 and p30) express a different pattern of CRFR1 isoforms in accordance with RT-PCR experiments. The bands of 37, 45 and $64 \mathrm{kDa}$ corresponded to processed, full-length and glycosylated CRFR $1 \alpha$ isoform respectively, as documented previously (Slominski et al. 2006a). In passage p24, we also detected bands of approximately 24 and $52 \mathrm{kDa}$, which could represent other isoforms of CRFR1 detected by RT-PCR (Fig. 3A
A

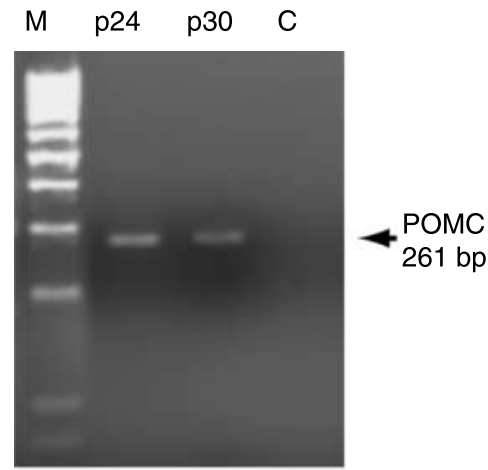

B

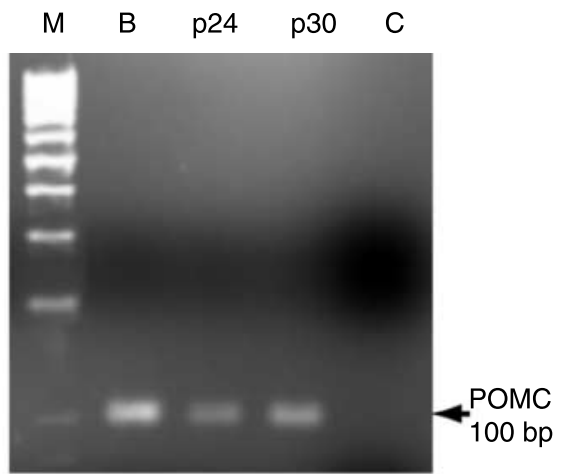

$E$

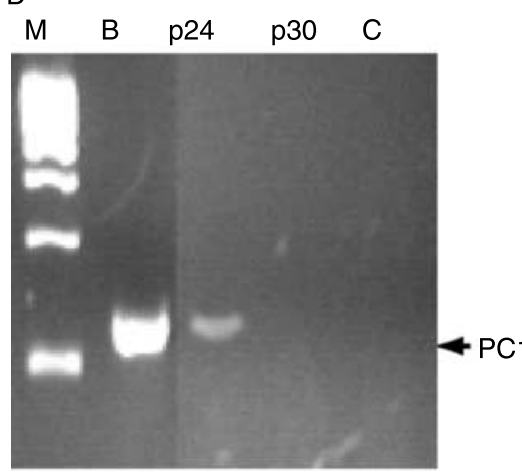

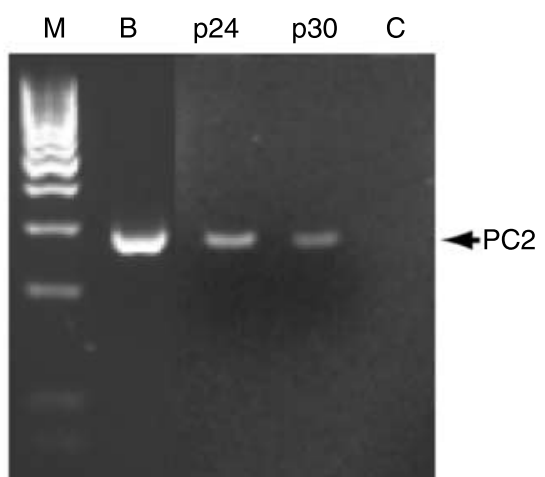

C

ARPE p24

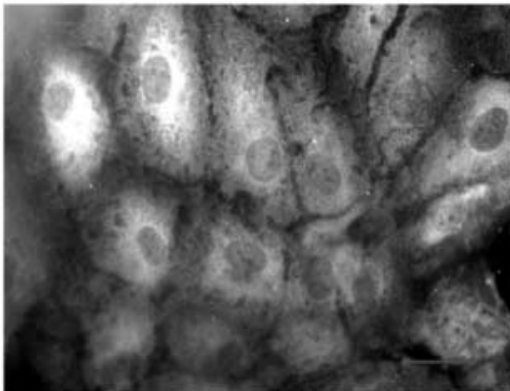

ARPE p30

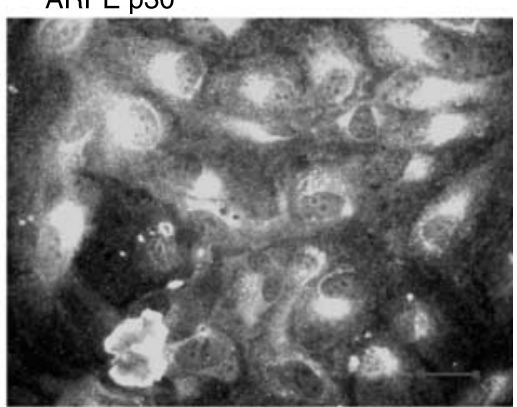

Figure 2 Expression of POMC (A and B), convertases PC1 and PC2 (D and E) mRNAs and ACTH $(C)$ in ARPE-19 cells. (A and B) Two different sets of primers were used for RT-PCR detection of fragments of POMC mRNA as published (Slominski et al. 1995, 2005). (C) Immunocytochemical detection of ACTH in human ARPE cells of passages 24 (p24) and 30 (p30). Colour panels and control experiments are shown in supplementary Fig. 1 (http://joe.endocrinology-journals.org/content/vol 193/issue 1/). Bar, $25 \mu \mathrm{m}$. RT-PCR detection of prohormone convertases: PC1, 674 bp (D) and PC2, $299 \mathrm{bp}$ (E). Primers and RT-PCR conditions are described in Materials and Methods section. On panels (A, B, D and E): DNA ladder, M; ARPE-19 passages 24, p24; and 30, p30; brain (positive control), B and negative control without cDNA, C. 
A

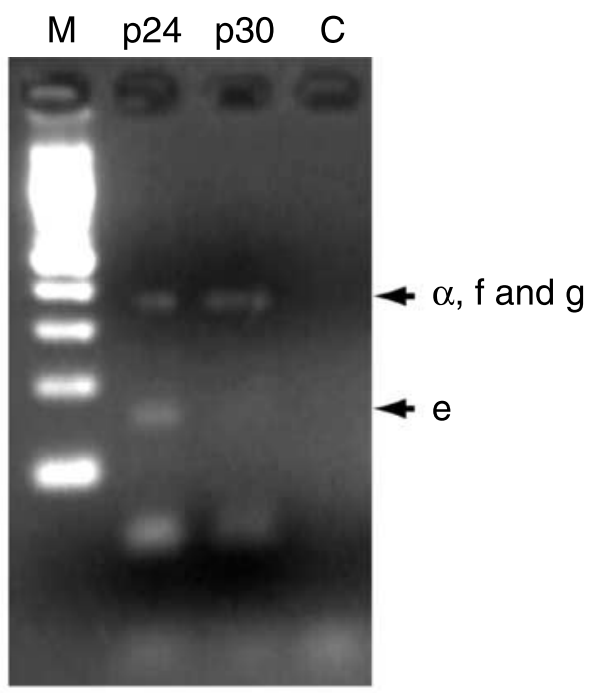

B

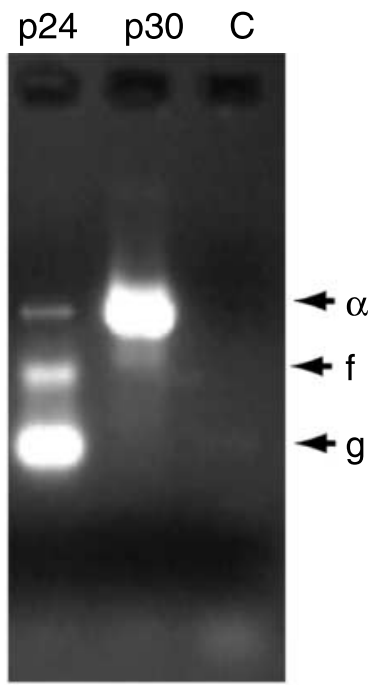

C

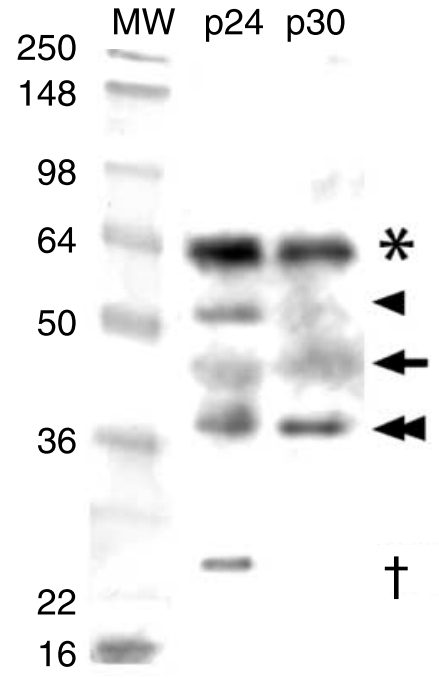

$\mathrm{D}$

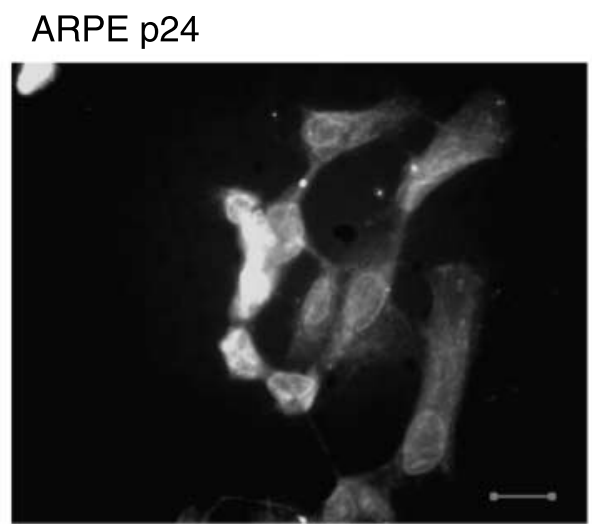

ARPE p30

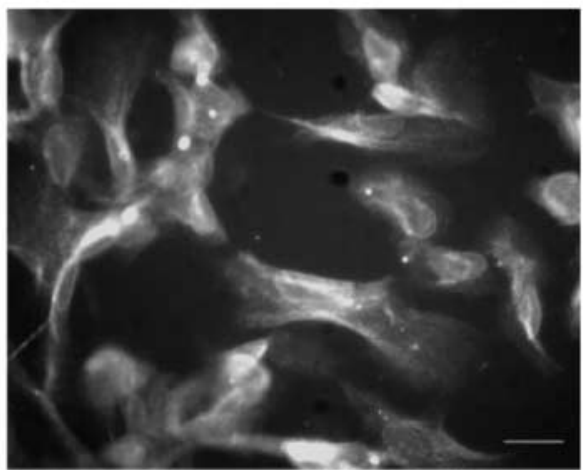

Figure 3 CRFR1 expression in ARPE-19 cells. (A) Nested RT-PCR with primers spanning exons 2-7 detects fragment 369 bp corresponding to isoforms CRFR1 $\alpha$, for $g$ and 163 bp corresponding to isoform CRFR1e. (B) Nested RT-PCR with primers spanning exons 9-14. Fragment of $336 \mathrm{bp}$ corresponds to isoform $\alpha$ and fragments 200 and $114 \mathrm{bp}$ correspond to isoforms CRFR1f and CRFR1g respectively. On panels A and B: $100 \mathrm{~kb}$ DNA ladder, M; ARPE-19 passages 24, p24; 30, p30; negative control without cDNA, C. Nested RT-PCRs were performed as described (Pisarchik \& Slominski 2001). (C) Western blotting detection of CRFR1. MW, molecular weight marker, *glycosylated receptor, arrow head - unprocessed full-length CRFR1 $\alpha$, arrow - CRFR1f or g, double-arrow head - processed CRFR1, ${ }^{+}$CRFR1e.

(D) Immunocytochemical detection of CRFR1 in human ARPE-19 cells, passages 24 (p24) and 30 (p30). Colour panels and control experiments are shown in supplementary Fig. 1 (http://joe.endocrinology-journals.org/content/vol193/issue1/). Bar, $25 \mu \mathrm{m}$.

and $\mathrm{B})$. The $24 \mathrm{kDa}$ band could represent glycosylated form of CRFR1e, which had a calculated molecular mass of $14 \mathrm{kDa}$ before glycosylation. The $52 \mathrm{kDa}$ band might correspond to the glycosylated CRFR1f and/or CRFR1g, which were detected by RT-PCR (Fig. 3A and B). The molecular masses of CRFR1f and CRFR1g before glycosylation are 39.1 and $43.13 \mathrm{kDa}$ respectively. It could be suggested that glycosylation would lead to approximately $10-15 \mathrm{kDa}$ shift in the molecular mass, similar to what was previously shown for CRFR $1 \alpha$ (Slominski et al. 2006a). Further confirmation of CRFR1 receptor protein expression in both passages of ARPE-19 cells was provided by immunocytochemistry (supplementary figure 1B and Fig. 3D).

\section{CRFR1 expressed in ARPE-19 cells is functional}

Stimulation of ARPE cells with CRF elevated the production of cAMP and $\mathrm{IP}_{3}$ in dose-specific and cell passage-specific manner (Fig. 4), indicating that CRFR1 receptor was functionally active. CRF triggered cAMP and $\mathrm{IP}_{3}$ production in ARPE-19 cells with the highest efficiency in late passages 

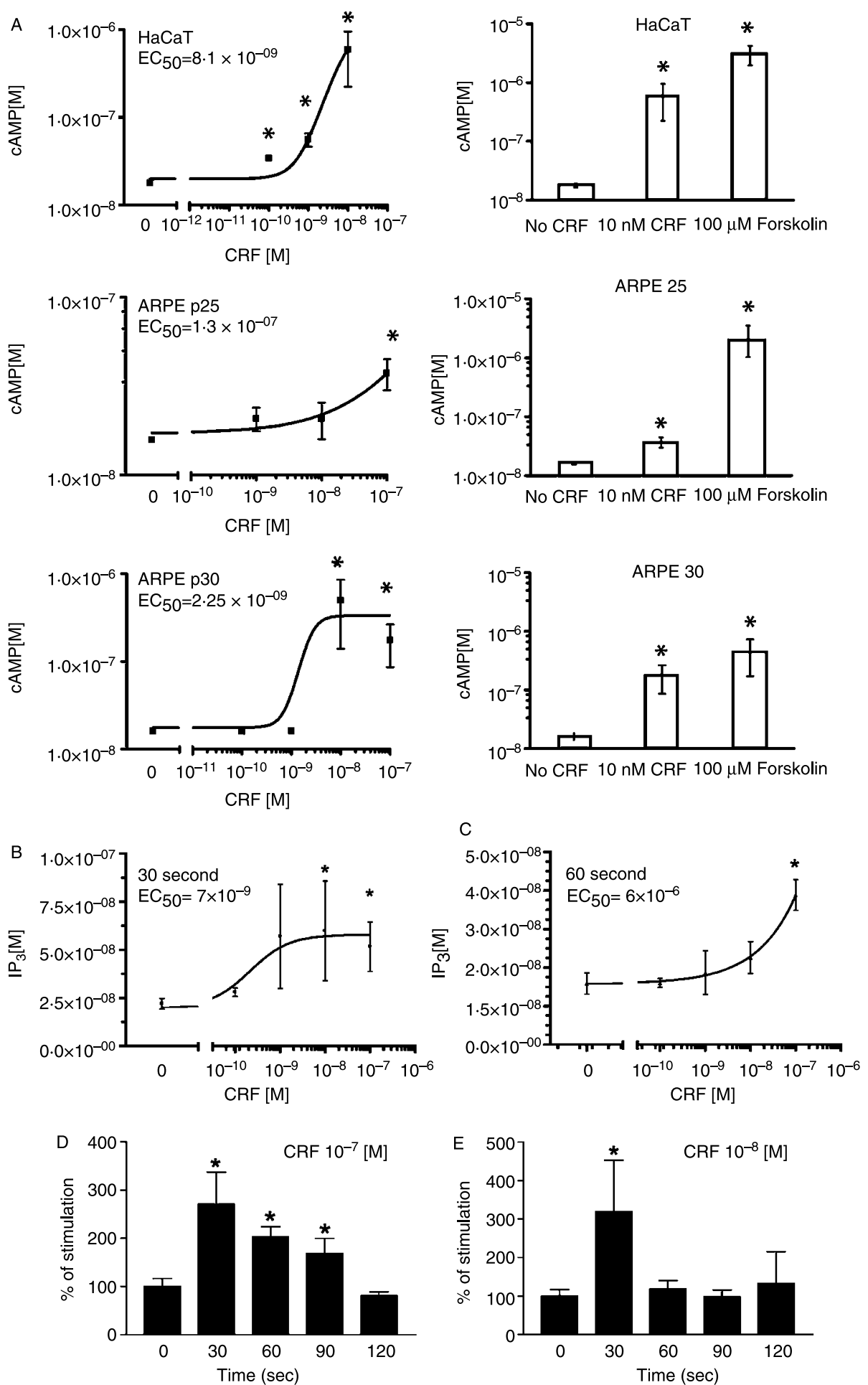

Figure 4 CRF stimulates production of $C A M P(A)$ and IP 3 production (B-E) in ARPE-19 cells. (A) Left panels present dose-response curves. Right panels, stimulation of CRF $100 \mathrm{nM}$ (10 nM for HaCaT) is compared with stimulation with forskolin (0.1 mM). Dose-response curves are obtained after $30 \mathrm{~s}$ (B) or $60 \mathrm{~s}(\mathrm{C})$ after stimulation with CRF. Time-dependent stimulation of IP 3 production in ARPE cells is shown for CRF doses of $10^{-7} \mathrm{M}$ (D) or $10^{-8} \mathrm{M}(\mathrm{E}) .{ }^{*} P<0.05$. 

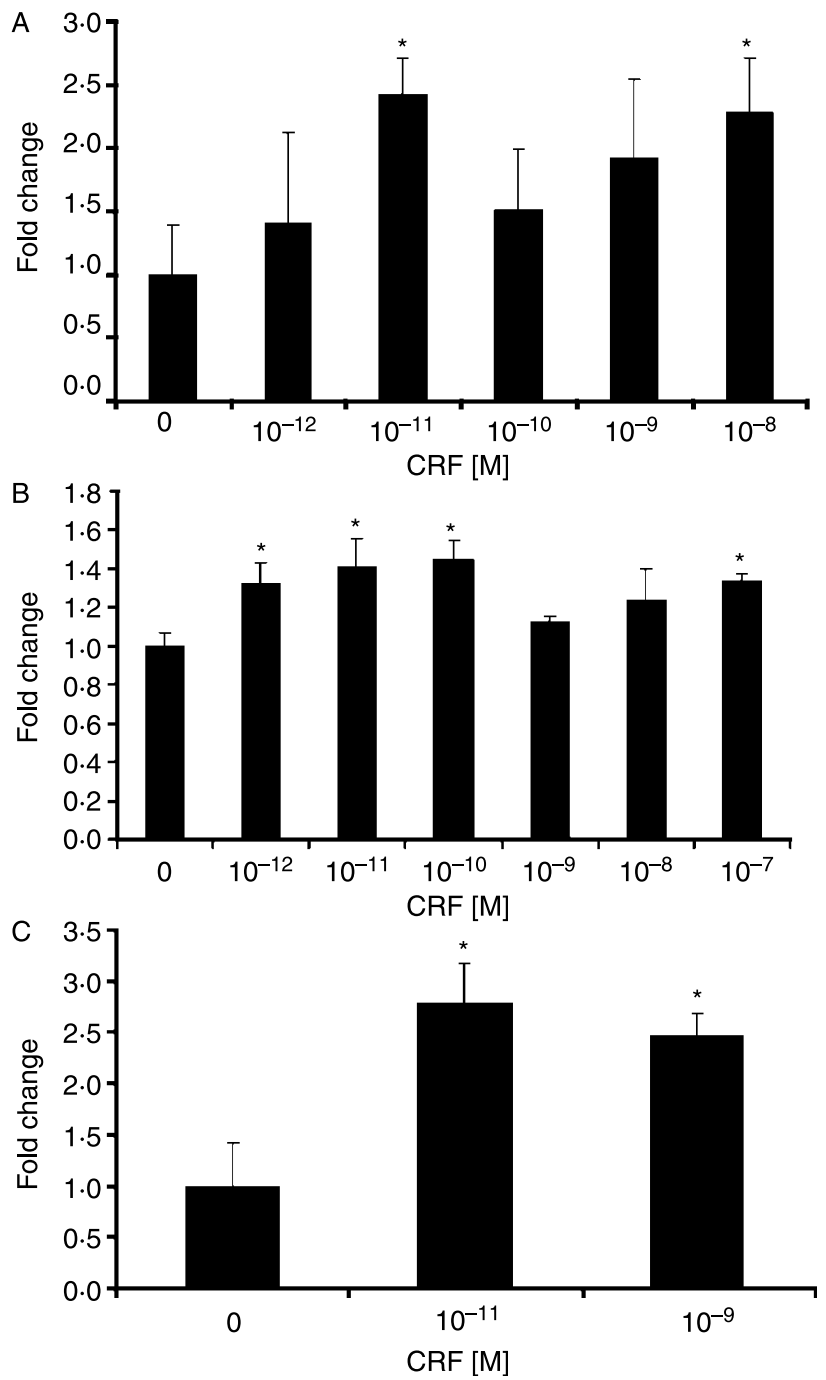

Figure 5 CRF stimulates transcriptional activity of CRE (A) and AP1 responsive elements (B) and POMC promoter (C). ARPE-19 cells, passages 25-28, were transiently transfected with firefly luciferase reporter gene constructs: pCRE-Luc (under control of CRE), pAP1-Luc (under control of AP1) and p-POMC-Luc (driven by the sequence of the human POMC promoter -771 to -8 ) and phRL-TK (Renilla luciferase used as transfection efficiency control; Pisarchik \& Slominski 2004, Slominski et al. 2005, Zbytek et al. 2006). The transiently transfected cells were treated with serial dilutions of CRF, lysed after $24 \mathrm{~h}$ after treatment and activity of the promoter measured. Data are presented as means \pm S.E.M. $(n=3) .{ }^{*} P<0.05$.

(Fig. 4). Specifically, the $\mathrm{EC}_{50}$ (effective concentration) for p25 was $1.3 \times 10^{-7}$, while in p30 $\mathrm{EC}_{50}$ was $2.25 \times 10^{-9}$, when compared with $8 \times 10^{-9}$ for control HaCaT keratinocytes (Fig. 4A). CRF also stimulated $\mathrm{IP}_{3}$ production in doseand time-dependent manner (Fig. 4B-E), with the highest activity $30 \mathrm{~s}$ after addition of the ligand $\left(\mathrm{EC}_{50}=7 \times 10^{-9}\right)$, but only in late passages of ARPE-19 cells (p30; Fig. 4B-E). The stimulation of $\mathrm{IP}_{3}$ production for $\mathrm{p} 24$ of ARPE-19 cells was below detectable levels (data not shown). The $\mathrm{EC}_{50}$ for $\mathrm{IP}_{3}$ production in ARPE-19 was comparable to that observed in normal epidermal keratinocytes (Zbytek \& Slominski 2005, Slominski et al. 2006a) and squamous cell carcinoma (Kiang 1995).

We also studied transcriptional activity of CRE and AP1 responsive elements and of human POMC promoter $(-771$ to -8) in human ARPE-19 cells, p25-28, using dual luciferase assay system and plasmids pCRE-Luc, pAP1-Luc and POMC-Luc as described (Pisarchik \& Slominski 2004, Slominski et al. 2005, Zbytek et al. 2006). CRF-stimulated transcriptional activity of CRE and AP1 reached maximal responses at different dose range, e.g. at $10^{-11}$ and $10^{-8} \mathrm{M}$ for CRE (Fig. 5A) and $10^{-10}$ and $10^{-7} \mathrm{M}$ for AP1 (Fig. 5B). These assays indicate that activation of second messengers' production by CRF leads to transcriptional activity of the corresponding regulatory elements (CRE and AP1). Dual effect at different dose range is unusual and may reflect co-expression of different isoforms of CRFR1 in APRE-19. The luciferase assay also demonstrated CRF stimulation of transcriptional activity of POMC promoter (Fig. 5C), indicating that activation of CRFR 1 can stimulate $P O M C$ gene transcription in human RPE cells.

\section{Expression of CYP11A1, CYP11B1, CYP17 and CYP21A2 genes and detection of cortisol in ARPE-19}

Using RT-PCR and a set of unique primers, we detected cDNA of four key enzymes, which take part in synthesis of glucocorticoids, namely cytochromes P450 side-chain cleavage (P450scc), 11- $\beta$-hydroxylase (P450c11), 17- $\alpha$ hydroxylase $(\mathrm{P} 450 \mathrm{c} 17)$ and 21-hydroxylase $(\mathrm{P} 450 \mathrm{c} 21)$ coded by CYP11A1, CYP11B1, CYP17 and CYP21A2 genes respectively (Payne \& Hales 2004). The nested RT-PCR product of $390 \mathrm{bp}$ (Fig. 6A) covering the region of exons 4-7 of CYP11A1 mRNA was as predicted (Slominski et al. 2004c). RT-PCR primers covering splicing sides between exons $8 / 9$ and $9 / 10$ were used to detect $215 \mathrm{bp}$ fragment of CYP11B1 (GenBank Accession number NM_000497, Fig. 6B). Nested primers spanning exons 2-3 for CYP17 (GenBank Accession number NM_000102) and exons 7-8 for CYP21A2 (GenBank Accession number NM_0005002) were used to amplify fragments of 222 and $199 \mathrm{bp}$ respectively. The presence of CYP17 transcript was detected only in early passage of ARPE-19 (p24, Fig. 6C), while the expression of other studied genes was detected in all tested passages (Fig. 6A, B and D).

In order to validate the physiological significance of the expression of the genes studied above, we tested for an accumulation of cortisol in conditioned media of APRE passage 28. The cortisol-immunoreactivity was detected in ARPE medium and its content was increased by the addition of progesterone. Furthermore, CRH or ACTH $\left(10^{-7} \mathrm{M}\right)$ also stimulated the accumulation of cortisol-immunoreactivity in culture medium (Fig. 6E). 
A

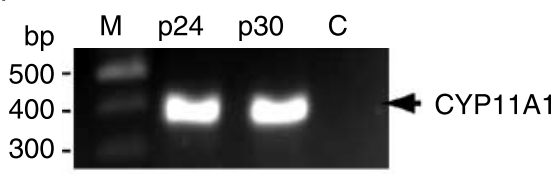

B

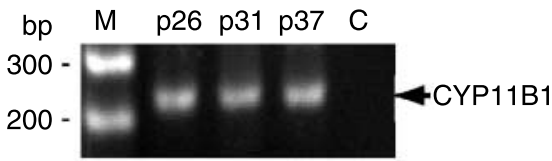

C

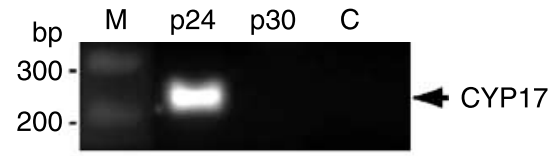

D

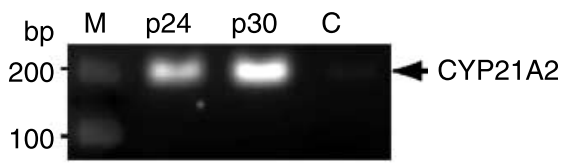

$E$

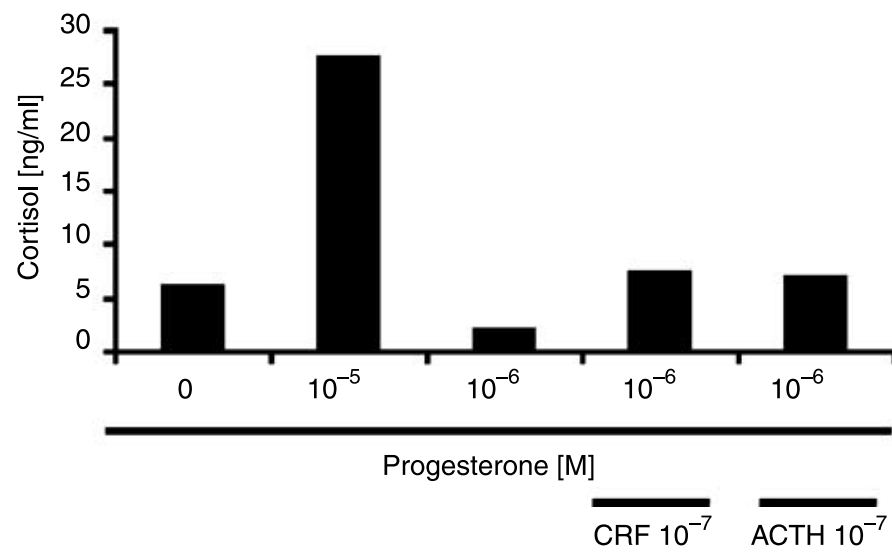

Figure 6 Expression of genes for $C Y P 11 A 1$ (A), CYP11B1 (B), CYP17 (C) and CYP21A2 (D) in human ARPE cells. Nested RT-PCRs were performed as described in Materials and Methods section and amplification on predicted fragments of CYP11A1, 390 bp; CYP11B1, 215 bp; CYP17, 222 bp and CYP21A2, 199 bp was detected. $100 \mathrm{~kb}$ DNA ladder, M; ARPE-19 passages 24, p24 and 30, p30 (A, C and D) or 26, p26; 31, p31; 37, p37 (B), negative control without CDNA, C. (E) Production of cortisol from progesterone was assayed by ELISA as described in the Materials and Methods section.

In situ detection of CRF, Ucn-I, CRFR1 and ACTH antigens in mouse eye

CRF, Ucn-I, CRFR1 and ACTH antigens were detected in formalin-fixed cryosections of mouse eye (Fig. 7). The specific anti-mouse antibodies for corticoliberin (precursor of CRF; sc-1761; Santa Cruz Biotechnology) and urocortin I (Ucn; sc-1825; Santa Cruz Biotechnology) were used to detect unprocessed peptides to assure that they are synthesised locally and were not derived from the central nervous system. Both precursor forms of peptides were detected predominantly in RPE cells and additionally in some cone photoreceptors, especially in the outer segments (Fig. 7A and B). CRFR1 immunoreactivity was predominantly detected in the basal parts of the RPE layer (Fig. 7C). ACTH was localised in the RPE mostly in the apical parts of the cells.

\section{Discussion}

Our results show for the first time that ARPE-19 cells, derived from adult human RPE, express the main genes involved in the HPA axis, e.g. CRF, Ucn I-III, CRFR1, POMC, PC1, PC2, CYP11A1, CYP11B1, CYP17 and CYP21A2, and produce CRF, Ucn I, CRFR1 and $\mathrm{POMC} / \mathrm{ACTH}$ protein products. The CRFR1 was functional as documented by the CRF stimulation of cAMP and $\mathrm{IP}_{3}$ production as well as by the stimulation of transcriptional activity of CRE, AP1 and human POMC promoter. Selected elements of the HPA axis (CRF, Ucn I, CRFR1 and ACTH) were also co-localised in situ in RPE layer of the mouse eye cross-section by immunocytochemistry. Thus, the molecular structure of the HPA axis is duplicated in RPE, which implies a role in the regulation of eye physiology and pathology. This is consistent with a proposed role of peripheral HPA homologue in the regulation of stress responses in another organ exposed to environmental insults - skin (Slominski \& Wortsman 2000, Slominski et al. 2000, 2006b, Slominski 2005).

Previous reports in an animal model of autoimmune uveitis have shown the presence of CRF immunoreactivity in the infiltrating immune cells at the site of inflammation including iris, ciliary body, vitreous, retina and choroid, suggesting a pathogenic autocrine or paracrine 

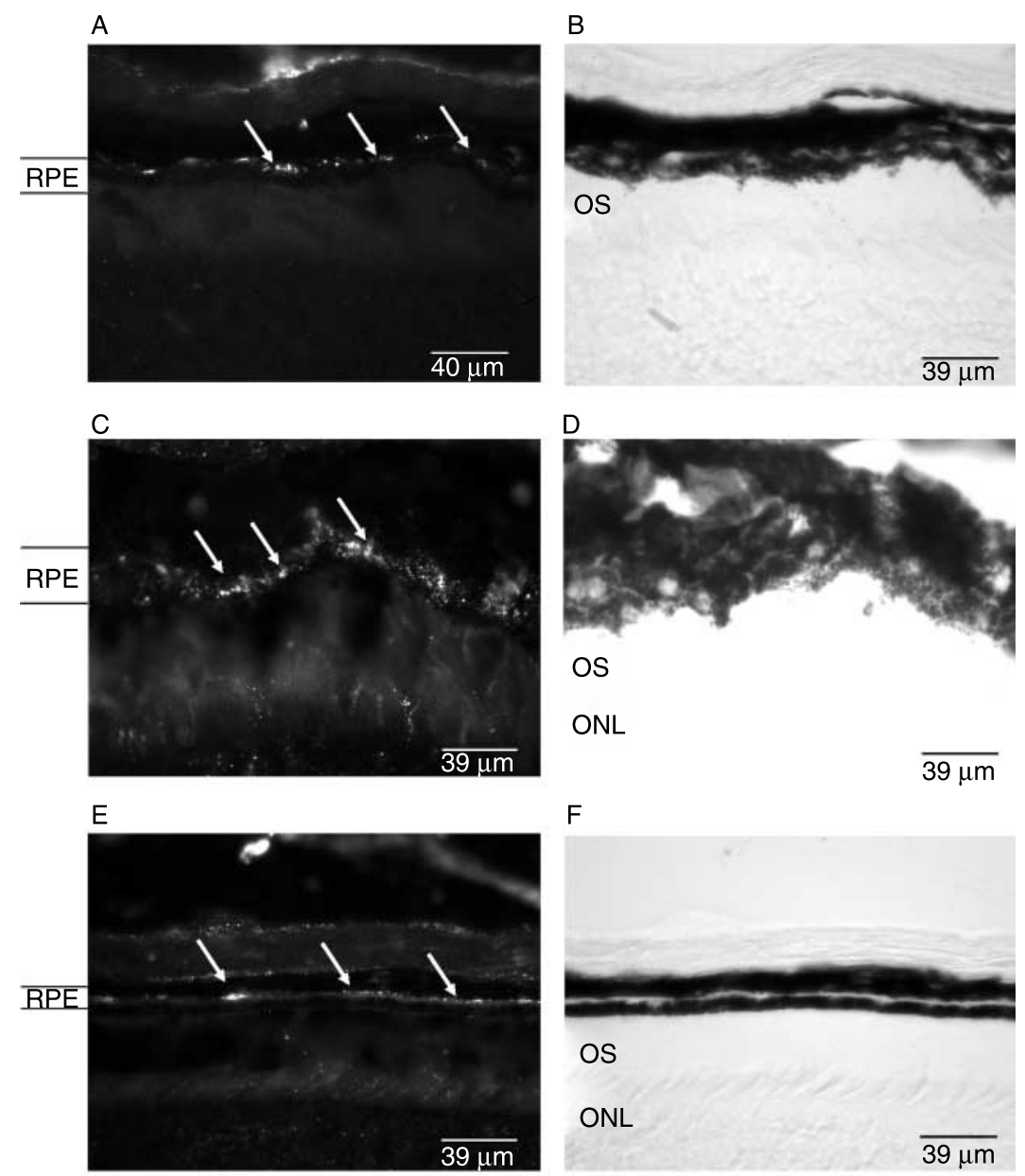

F
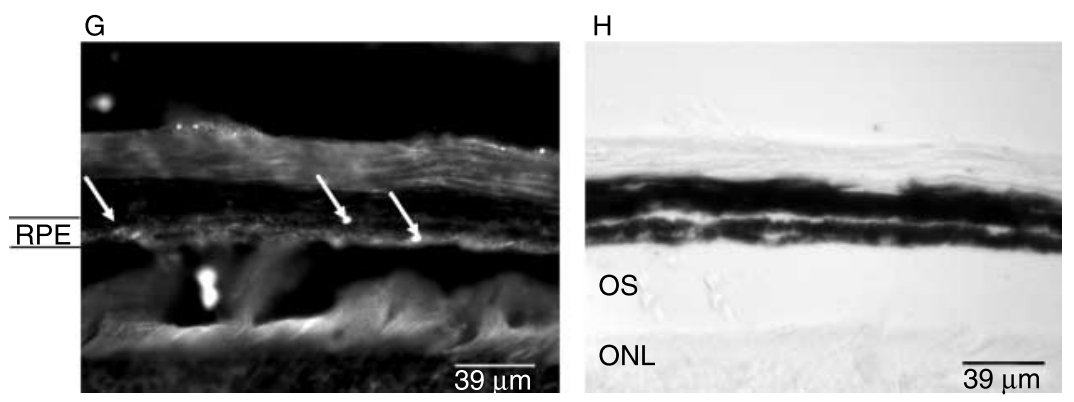

Figure 7 Localisation of immunoreactivities characteristic for the hypothalamic-pituitaryadrenal axis in mouse eye. Immunohistochemical detection of (A) CRF precursor, (C) preurocortin, (E) CRFR1 and (G) ACTH. Panels (A), (C), (E), (G) represent fluorescent and panels $(B),(D),(F),(H)$ bright field images of the same areas. OS, outer segments; ONL, outer nuclear layer; RPE, retinal pigment epithelium.

proinflammatory role of CRF (Mastorakos et al. 1995). Our results indicate that the CRF detected in the eye, at least partially, originates from the RPE cells. Furthermore, since CRF stimulates cAMP production in the retina of different mammals (Olianas \& Onali 1990, Olianas et al. 1993), we propose that retinal cells can also be directly activated by CRF or urocortin synthesised by RPE in addition to the
CNS-derived peptides. RPE cells could be a target of CRF and related peptides, since we have shown production of cAMP and $\mathrm{IP}_{3}$ followed by transcriptional activation of CRE and AP1 responsive elements and, finally, stimulation of POMC promoter.

The pattern of expression of CRFR1 isoforms changed with the age of ARPE-19 primary culture, which might 
contribute to the observed changes in CRFR 1 signalling. We observed efficient stimulation of cAMP and $\mathrm{IP}_{3}$ production by exogenous ligand only in late passages of APRE-19 cells (p30) after stimulation with CRF. This change in the responsiveness of the receptor may be secondary to either decreased production of CRF by APRE-19 cells, which desensitises receptor to exogenous ligand (paracrine action), or modifying action of isoforms CRFR1f and/or CRFR1g that are expressed only during early passages. The presence of several isoforms of CRFR1 might also explain the dual effect at different dose range observed for CRE and AP1 responsive elements. This is in agreement with our suggestions that the expression of CRFR1f and/or CRFR1g can interfere with CRF signalling through the main isoform - CRFR $1 \alpha$, thus modifying its signal transduction pathway (Pisarchik \& Slominski 2001, 2004, Slominski et al. 2006b).

Expression of prohormone convertases PC1 and PC2, POMC and detection of ACTH immunoreactivity in human ARPE cells is in agreement with the detection of PC1, PC2 and $\alpha-\mathrm{MSH}$ (a direct derivative of ACTH) in avian RPE cells, the cone photoreceptors/neural retina (Teshigawara et al. 2001) and in the eye sections (Takeuchi et al. 2001, Teshigawara et al. 2001). Additional demonstration of CRF-induced production of second messengers and stimulation of transcriptional activity of CRE, AP1 and POMC promoter in ARPE cells suggest that the production of the neuropeptides can be regulated locally in the eye in response to environmental stimuli similar to that observed in the skin (Slominski et al. 2000, 2001, 2005, 2006b). Interestingly, receptor for melanocortins and $\mathrm{ACTH}\left(\mathrm{MC}_{5}\right)$ was detected in outer segments of photoreceptors (Lindqvist et al. 2003) and $\mathrm{MC}_{3}$ and $\mathrm{MC}_{4}$ receptors were found in other parts of the retina, suggesting that ACTH and/or $\boldsymbol{\alpha}-\mathrm{MSH}$ production by $\mathrm{RPE}$ cells can affect photoreceptor physiology.

Detection of CYP11A1, CYP11B1, CYP17 and $C Y P 21 A 2$ (crucial genes of the steroidogenic pathway (Payne \& Hales 2004)) suggests that human ARPE cells may have corticosteroidogenic capability similar to skin pigment cells (Slominski \& Mihm 1996, Slominski et al. 1999, 2004c, 2005). This is further supported by data indicating production of cortisol-immunoreactivity from progesterone in RPE. However, the hypothesis on steroidogenic activity of ARPE requires further validation by testing for regulated enzymatic activity of the protein products of the above genes detected in RPE cells together with assessment of the expression of the $3 \beta \mathrm{HSD}$ in RPE. Expression of the $3 \beta \mathrm{HSD}$ activity has already been documented in skin cells (reviewed in (Slominski \& Wortsman 2000, Slominski 2005)).

Lastly, dysfunction of RPE cells plays a pivotal role in the pathogenesis of age-related macular degeneration (AMD), a major cause of visual impairment in ageing population (Sharma et al. 1995), in which inflammatory pathways might be important aetiological factors (Anderson et al. 2002). In this context, regulated production of intermediates of local HPA axis may play a role in eye function including prevention or attenuation of AMD, a subject that deserves further basic and translational studies.

In summary, we show that molecular elements of the HPA axis are expressed in adult human RPE cells indicating a novel mechanism for the local regulation of stress response in the eye and suggesting wider conservation of an HPA-like algorithm in peripheral tissues.

\section{Acknowledgements}

The work was supported by National Institutes of Health grants AR047079 and AR052190 (A S), grant from Gail and Richard Siegal, the Hyde Foundation, NEI grant EY-13080 and an unrestricted grant from Research to Prevent Blindness. Confocal microscopy was performed using the equipment obtained through Shared Instrumentation Grant from National Center for Research Purposes at the National Institutes of Health (S10 RR13725-01). The authors thank R Slominski for editing the manuscript. The authors declare that there is no conflict of interest that would prejudice the impartiality of this scientific work.

\section{References}

Aguilera G 1998 Corticotropin releasing hormone, receptor regulation and the stress response. Trends in Endocrinology and Metabolism 9 329-336.

Anderson DH, Mullins RF, Hageman GS \& Johnson LV 2002 A role for local inflammation in the formation of drusen in the aging eye. American Journal of Ophthalmology 134 411-431.

Bagnoli P, Dal Monte M \& Casini G 2003 Expression of neuropeptides and their receptors in the developing retina of mammals. Histology and Histopathology 18 1219-1242.

Bamberger CM, Wald M, Bamberger AM, Ergun S, Beil FU \& Schulte HM 1998 Human lymphocytes produce urocortin, but not corticotropinreleasing hormone. Journal of Clinical Endocrinology and Metabolism $\mathbf{8 3}$ $708-711$.

Chrousos GP 1995 The hypothalamic-pituitary-adrenal axis and immunemediated inflammation. New England Journal of Medicine 332 1351-1363.

Grammatopoulos DK \& Chrousos GP 2002 Functional characteristics of $\mathrm{CRH}$ receptors and potential clinical applications of CRH-receptor antagonists. Trends in Endocrinology and Metabolism 13 436-444.

Hillhouse EW \& Grammatopoulos DK 2006 The molecular mechanisms underlying the regulation of the biological activity of corticotropinreleasing hormone receptors: implications for physiology and pathophysiology. Endocrinology Review 27 260-286.

Imperatore A, Florio P, Torres PB, Torricelli M, Galleri L, Toti P, Occhini R, Picciolini E \& Vale W 2006 Urocortin 2 and urocortin 3 are expressed by the human placenta, deciduas, and fetal membranes. American Journal of Obstetrics and Gynecology 195 288-295.

Kempuraj D, Papadopoulou NG, Lytinas M, Huang M, Kandere-Grzybowska K, Madhappan B, Boucher W, Christodoulou S, Athanassiou A \& Theoharides TC 2004 Corticotropin-releasing hormone and its structurally related urocortin are synthesized and secreted by human mast cells. Endocrinology 145 43-48.

Kiang JG 1995 Mystixin-7 and mystixin-11 increase cytosolic free $\mathrm{Ca}^{2+}$ and inositol trisphosphates in human A-431 cells. European Journal of Pharmacology 291 107-113.

Lin TC, Chien SC, Hsu PC \& Li LA 2006 Mechanistic study of polychlorinated biphenyl 126-induced CYP11B1 and CYP11B2 up-regulation. Endocrinology 147 1536-1544. 
Lindqvist N, Napankangas U, Lindblom J \& Hallbook F 2003 Proopiomelanocortin and melanocortin receptors in the adult rat retino-tectal system and their regulation after optic nerve transection. European Journal of Pharmacology 482 85-94.

Linton EA, Woodman JR, Asboth G, Glynn BP, Plested CP \& Bernal AL 2001 Corticotrophin releasing hormone: its potential for a role in human myometrium. Experimental Physiology 86 273-281.

Mastorakos G, Bouzas EA, Silver PB, Sartani G, Friedman TC, Chan CC, Caspi RR \& Chrousos GP 1995 Immune corticotropin-releasing hormone is present in the eyes of and promotes experimental autoimmune uveoretinitis in rodents. Endocrinology $1364650-4658$.

Olianas MC \& Onali P 1990 Presence of corticotropin-releasing factorstimulated adenylate cyclase activity in rat retina. Journal of Neurochemistry $\mathbf{5 4}$ 1967-1971.

Olianas MC, Loi V, Lai M, Mosca E \& Onali P 1993 Corticotropin-releasing hormone stimulates adenylyl cyclase activity in the retinas of different animal species. Regulatory Peptides 47 127-132.

Payne AH \& Hales DB 2004 Overview of steroidogenic enzymes in the pathway from cholesterol to active steroid hormones. Endocrine Reviews $\mathbf{2 5}$ 947-970.

Perrin MH \& Vale WW 1999 Corticotropin releasing factor receptors and their ligand family. Annals of the New York Academy of Sciences 885 312-328.

Pisarchik A \& Slominski AT 2001 Alternative splicing of CRH-R1 receptors in human and mouse skin: identification of new variants and their differential expression. FASEB Journal 15 2754-2756.

Pisarchik A \& Slominski A 2004 Molecular and functional characterization of novel CRFR1 isoforms from the skin. European Journal of Biochemistry 271 2821-2830.

Pisarchik A, Wortsman J \& Slominski A 2004 A novel microarray to evaluate stress-related genes in skin: effect of ultraviolet light radiation. Gene 341 199-207.

Selye H 1936 A syndrome produced by various noxious agents. Nature London 138 32-33.

Sharma RK \& Ehinger B 2003 Development and Structure of the Retina. In Adler's Physiology Of The Eye: Clinical Application, edn 10, Eds PL Kaufman \& A Alm. Saint Louis: Mosby.

Sharma RK, Bergström A \& Ehinger B 1995 Retinal cell transplants. Progress in Retinal and Eye Research 15 197-230.

Slominski A 2005 Neuroendocrine system of the skin. Dermatology 211 199-208.

Slominski A \& Mihm MC 1996 Potential mechanism of skin response to stress. International Journal of Dermatology 35 849-851.

Slominski A \& Wortsman J 2000 Neuroendocrinology of the skin. Endocrinology Review 21 457-487.

Slominski A, Ermak G, Hwang J, Chakraborty A, Mazurkiewicz JE \& Mihm M 1995 Proopiomelanocortin, corticotropin releasing hormone and corticotropin releasing hormone receptor genes are expressed in human skin. FEBS Letters 374 113-116.

Slominski A, Gomez-Sanchez CE, Foecking MF \& Wortsman J 1999 Metabolism of progesterone to DOC, corticosterone and 18OHDOC in cultured human melanoma cells. FEBS Letter 455 364-366.
Slominski A, Wortsman J, Luger T, Paus R \& Solomon S 2000 Corticotropin releasing hormone and proopiomelanocortin involvement in the cutaneous response to stress. Physiological Reviews 80 979-1020.

Slominski A, Wortsman J, Pisarchik A, Zbytek B, Linton EA, Mazurkiewicz JE \& Wei ET 2001 Cutaneous expression of corticotropin-releasing hormone (CRH), urocortin, and CRH receptors. FASEB Journal 15 1678-1693.

Slominski A, Tobin DJ, Shibahara S \& Wortsman J 2004a Melanin pigmentation in mammalian skin and its hormonal regulation. Physiological Reviews 84 1155-1228.

Slominski A, Pisarchik A, Tobin DJ, Mazurkiewicz JE \& Wortsman J $2004 b$ Differential expression of a cutaneous corticotropin-releasing hormone system. Endocrinology 145 941-950.

Slominski A, Zjawiony J, Wortsman J, Semak I, Stewart J, Pisarchik A, Sweatman T, Marcos J, Dunbar C \& Tuckey RC 2004c A novel pathway for sequential transformation of 7-dehydrocholesterol and expression of the P450scc system in mammalian skin. European Journal of Biochemistry 271 4178-4188.

Slominski A, Zbytek B, Szczesniewski A, Semak I, Kaminski J, Sweatman T \& Wortsman J 2005 CRH stimulation of corticosteroids production in melanocytes is mediated by ACTH. American Journal of Physiology. Endocrinology and Metabolism 288 E701-E706.

Slominski A, Zbytek B, Pisarchik A, Slominski RM, Zmijewski MA \& Wortsman J 2006a CRH functions as a growth factor/cytokine in the skin. Journal of Cellular Physiology 206 780-791.

Slominski AT, Zbytek B, Zmijewski MA, Slominski RM, Kauser S, Wortsman J \& Tobin DJ $2006 b$ Corticotropin releasing hormone and the skin. Frontiers in Bioscience 11 2230-2248.

Takeuchi S, Haneda M, Teshigawara K \& Takahashi S 2001 Identification of a novel GH isoform: a possible link between $\mathrm{GH}$ and melanocortin systems in the developing chicken eye. Endocrinology 142 5158-5166.

Teshigawara K, Takahashi S, Boswell T, Li Q, Tanaka S \& Takeuchi S 2001 Identification of avian alpha-melanocyte-stimulating hormone in the eye: temporal and spatial regulation of expression in the developing chicken. Journal of Endocrinology 168 527-537.

Vale W, Spiess J, Rivier C \& Rivier J 1981 Characterization of a 41-residue ovine hypothalamic peptide that stimulates secretion of corticotropin and beta-endorphin. Science 213 1394-1397.

Zbytek B \& Slominski AT 2005 Corticotropin-releasing hormone induces keratinocyte differentiation in the adult human epidermis. Journal of Cellular Physiology 203 118-126.

Zbytek B, Wortsman J \& Slominski A 2006 Characterization of a ultraviolet B-induced corticotropin-releasing hormone-proopiomelanocortin system in human melanocytes. Molecular Endocrinology 20 2539-2547.

\section{Received in final form 29 December 2006 Accepted 4 January 2007 Made available online as an Accepted Preprint 12 January 2007}

